\title{
POR QUE DEVERÍAMOS GIRAR O EIXO DA INVESTIGAÇÃO?
}

\section{Método Filosófico em §§89-133 das Investigações Filosóficas}

\author{
Rafael Graebiin Vogelmann ${ }^{1}$
}

\begin{abstract}
RESUMO
Os parágrafos $\S \S 108-133$ das Investigações Filosóficas de Wittgenstein parecem conter lembretes sobre o que se deve e não se deve fazer quando se faz filosofia: não se deve apresentar teorias $(\S 109)$ nem tocar no uso efetivo da linguagem $(\S 124)$; deve-se, por outro lado, reconduzir as palavras de um emprego metafísico para um emprego cotidiano (§116), simplesmente apresentar as coisas, sem explicá-las (§126). Mas se o modo correto de fazer filosofia é apenas descrever o que está ao alcance da vista, o que justificaria estas considerações normativas? Se o que ele tem a oferecer são descrições, como ele pode apresentar considerações sobre a filosofia a quais a própria tradição filosófica parece não se conformar? Argumentaremos que estas passagens contêm recomendações metodológicas. Elas, porém, não são resultado direto da aplicação do método, i.e., não são algo que descobrimos a respeito da filosofia usando o método ele mesmo. As considerações metodológicas são justificadas porque são resultado de um processo de deliberação fidedigno. $\mathrm{O}$ que torna o processo deliberativo fidedigno é o fato de que a aplicação do método nos fornece uma descrição acurada do fim que a prática filosófica tradicionalmente tem em vista, de maneira a nos equipar para deliberar corretamente.
\end{abstract}

Palavras-chave: Wittgenstein; Investigações Filosóficas; Método Descritivo; Normatividade; Deliberação.

\begin{abstract}
Paragraphs $\S \S 108-133$ of Wittgenstein's Philosophical Investigations seems to contain reminders about what we should and should not do when we do philosophy: we should neither present theories $(\S 109)$ nor interfere with the actual use of language $(\S 124)$; we should, on the other hand, bring the words back from their metaphysical use to their everyday use (§116) and simply present things, without explaining them $(\S 126)$. But if the correct way of doing philosophy is just to describe what lies open to view, what justifies those normative considerations? If everything he has to offer are descriptions, how can he make considerations about philosophy to which the philosophical tradition apparently does not comply? We will argue that these passages do contain methodological recommendations. Those, however, are not the immediate result of the application of the method, i.e., they are not something we discover about philosophy by employing the method itself. The methodological considerations are justified because they are the result of a reliable process of deliberation. What makes the deliberative process reliable is the fact that the application of the method provides us with an accurate description of the goal that the philosophical practice traditionally has in view, thus enabling us to deliberate correctly.
\end{abstract}

Keywords: Wittgenstein; Philosophical Investigations; Descriptive Method; Normativity; Deliberation.

\footnotetext{
${ }^{1}$ Graduando UFRGS
} 


\section{Formulando o Problema}

Em geral, recomendações metodológicas não são tais que sua aplicação permita mostrar a validade das recomendações elas mesmas. Esse é o caso, por exemplo, do método científico: não há nada como experiências controladas que possamos fazer para testar hipóteses a respeito do método correto de se fazer pesquisa científica - não chegamos a nossa concepção do método científico realizando experimentos. E como poderíamos? A adequação do método científico deve ser averiguada por outros meios, sob pena de circularidade. As recomendações do método científico estão, por assim dizer, antes da pesquisa científica; não são teses científicas submetidas ao mesmo modo de crítica. Uma sugestão usual é que a validade do método deve ser atestada por meio da reflexão filosófica. Contudo, isso colocaria um problema quanto à noção de método filosófico: como decidimos sobre como fazer filosofia? A sugestão imediata de que apelaríamos a uma filosofia de segunda ordem é rapidamente afastada se nos perguntamos como decidiríamos sobre o método desta nova filosofia - vemos que postular uma filosofia de ordem superior apenas recoloca a questão e leva a um regresso infinito. Como decidimos então? Parece que temos que atribuir ao método filosófico (a certo modo de fazer filosofia) a peculiaridade de ser tal que sua aplicação permita mostrar a validade das recomendações metodológicas que são elas mesmas feitas (e de alguma forma evitar a circularidade nesse processo). Mas como isso poderia ser feito?

Nas Investigações $\S \S 108-133$ Wittgenstein apresenta o que parece ser um conjunto de recomendações metodológicas. Como nota Stern (2004, p.132), esses parágrafos apresentam um estilo de escrita bastante diferente do que é encontrado nos parágrafos anteriores. Se antes nos deparávamos com um confronto explícito entre duas vozes distintas (às vezes distinguidas graficamente no texto, por recurso a aspas ou travessões) ou com um narrador que nos apresentava ao que ele imaginava ou esperava que o interlocutor dissesse (geralmente indicado pelo uso de expressões como "suponha que alguém dissesse" ou "alguém poderia objetar"), agora nos deparamos com um texto muito mais assertivo, no qual não há distinção clara nem sugerida entre narrador e interlocutor. Mulhall descreve o caráter destas seções, em oposição ao caráter dialógico que caracteriza o texto que as precede, como o aparecimento de "uma voz autoritária" que se ocupa de "dar a lei” (MULHALL, 2004, p.68). A imagem de alguém que legisla captura tanto o tom autossuficiente das seções como 
o aspecto normativo das considerações feitas ali. O contraste de estilo pode ser explicado pelo fato de que $\S \S 108(b)-133$ datam de 1931 enquanto $\S \S 89-108$ (a) foram escritos seis anos mais tarde, em 1937 (MULHALL, 2004, p.63). O fato, contudo, de que Wittgenstein optou por utilizar as passagens de 1931 e conservar seu caráter assertivo e autoritário, reforça a convicção de que ele está apresentando aspectos de sua concepção positiva de filosofia.

Tanto o caráter taxativo como o uso mais do que ocasional de "deve" indicam que os parágrafos em questão contêm lembretes de caráter normativo, sobre o que se deve e não se deve fazer quando se faz filosofia: não se deve apresentar teorias ou buscar acúmulo de novas experiências (§109), tocar o uso efetivo da linguagem (\$124), buscar a resolução de contradições por meio de descobertas lógicas $(\S 125)$ ou apresentar teses $(\S 128)$; deve-se, por outro lado, reconduzir as palavras de um emprego metafísico para um emprego cotidiano (§116), descrever seu uso (§124), simplesmente apresentar as coisas, sem explicá-las ou tirar delas conclusões $(\S 126)$ - o trabalho do filósofo é acumular lembretes para certa finalidade $(\S 127)$.

Mas como Wittgenstein justifica essas considerações metodológicas? Temos alguma razão para supor que a proposta metodológica de Wittgenstein tem a peculiaridade de atender ao suposto desiderato de métodos filosóficos enunciados acima, qual seja: ser capaz de mostrar a validade das recomendações metodológicas elas próprias? Parece que não. As considerações metodológicas de Wittgenstein parecem não só não atender o desiderato como levar a um resultado oposto, pois, à primeira vista, sua aplicação não poderia justificar considerações normativas e, se pudesse, levaria a uma concepção do método filosófico que não é aquela que Wittgenstein apresenta.

Ver isto não é difícil. Se de fato o que temos em $\S \S 108-133$ são recomendações metodológicas, um aspecto marcante dessas recomendações é a recusa da teorização e a ênfase na necessidade de se limitar à descrição. Em §109, por exemplo, Wittgenstein afirma que "não devemos construir nenhuma espécie de teoria. [...] Toda elucidação deve desaparecer e ser substituída apenas por descrição"l. Outros exemplos poderiam ser apresentados, como a afirmação em $\$ 124$ de que a filosofia só pode descrever o uso da 
linguagem ou em $\S 126$ de que tudo que nos interessa está ao alcance da vista. Por ora, contudo, basta reconhecer que um aspecto marcante das recomendações metodológicas de Wittgenstein é a exigência de que o filósofo se limite a descrever aquilo que está na superfície, não oculto.

Voltaremos a considerar este aspecto do método proposto mais tarde. Agora quero apenas notar que diante disto surgem algumas perguntas. Em especial, se o modo correto de fazer filosofia é apenas descrever o que está ao alcance da vista, o que justificam considerações normativas como as que são feitas em $\S \S 108-133$ ? Se vamos nos limitar a descrever, podemos, no que diz respeito ao método filosófico, apenas descrever um método já utilizado - podemos apenas dizer "é assim que fazemos" (ou, mais plausível, "é assim que este filósofo procede; este outro procede desta maneira diferente; ainda este outro o faz de maneira diferente dos outros dois,...”) e não importa quão bem acabada for nossa descrição da prática filosófica vigente, parece que nunca poderemos passar destas considerações descritivas, sobre o que é o caso, para considerações normativas, sobre o que deveria ser o caso. Teríamos, parece, de escolher entre considerar as seções $\S \S 108-133$ como um deslize de Wittgenstein ou tentar lê-las de maneira a não tomá-las como oferecendo considerações normativas sobre como se deve fazer filosofia. Porém, suponha que houvesse algum modo de passar de considerações descritivas a normativas, ainda parece haver algo de errado com as seções em questão se elas são lidas como apresentando um resultado da aplicação do método que recomendam. Se o que o filósofo faz é apresentar uma "visão panorâmica" (§122), como poderia ele, na sua abordagem filosófica da própria filosofia, apresentar considerações metodológicas às quais a tradição filosófica parece não se conformar? Se o que ele oferece são descrições, então ele parece ter descrito de maneira incorreta a tradição filosófica, pois não foram poucos os filósofos que pretenderam ir além da descrição e apresentar teorias substantivas sobre os mais diversos temas. E se queremos descrever a filosofia, o que podemos descrever senão essa tradição ela mesma?

No que se segue não pretendo mostrar que Wittgenstein de alguma forma prova a correção de seu método, nem pretendo mostrar em detalhes que método é esse. Minha preocupação é com (i) mostrar que temos razão para supor que ele está de fato apresentando recomendações metodológicas e (ii) determinar em que medida elas recebem justificação e como a aplicação 
destas recomendações metodológicas elas mesmas podem contribuir para esta justificação.

\section{Há realmente um método sendo defendido?}

Aponto para (i), pois não é incontroversa a tese de que Wittgenstein apresenta considerações normativas. Stern (2004, p.126) defende que não é evidente que o que está sendo apresentado em $\S \S 108-133$ seja uma concepção positiva de um método filosófico. Embora ele reconheça (p.124) que a posição predominante na literatura é que em §89-133 é apresentada uma concepção da natureza da filosofia que culmina na discussão do método (ver MCGUINN, 2002, p.73, e BAKER \& HACKER, 2005, p.251) e que muitas das passagens nestas seções se prestam a esta leitura, Stern sustenta que afirmar que um método ou concepção geral de filosofia está sendo oferecido ali só é possível se ignorarmos uma importante alternativa de leitura, que ele chama de "leitura pirrônica" (STERN, 2004, p.125). Segundo Stern, a questão é se uma concepção positiva de filosofia está sendo apresentada ou se trata-se apenas de objeções a qualquer uso filosófico da linguagem (STERN, 2004, p.126).

Uma leitura pirrônica é tal que resiste a atribuir a Wittgenstein teses positivas. Essa leitura leva a sério a aversão à teorização que transparece no texto (por exemplo, em §109 ou §126) e procura tratar passagens nas quais uma filosofia positiva parece ser oferecida como um ataque a qualquer filosofia positiva. Se a empreitada pirrônica fosse bem-sucedida poderíamos, enfim, parar de fazer filosofia porque não seríamos mais fustigados "por questões que colocam ela própria [a filosofia] em questão" (§133).

Uma leitura pirrônica das seções que estamos considerando trataria os apelos ao cotidiano e à linguagem ordinária, aparentes em passagens como "nós reconduzimos as palavras de seu emprego metafísico para seu emprego cotidiano" (§116), não como exposição de um aspecto de um método que toma a linguagem ordinária como ponto de partida dogmático, mas como fonte de exemplos de alternativas aos pronunciamentos de filósofos para o efeito de que a linguagem deve funcionar de certo modo (ver STERN, 2004, p.127). Não apelaríamos ao uso ordinário da linguagem para, a partir daí, buscar conclusões filosóficas, mas apenas para resistir à teorias filosóficas. O apelo a estes exemplos para objetar teorias filosóficas não 
atribuiria ao uso cotidiano o papel de um padrão por meio do qual rejeitar o uso filosófico das palavras. A ideia é que por meio de sucessivas objeções deste tipo, sem tomar nem o uso ordinário nem o uso metafísico das palavras como privilegiado, poderíamos gradualmente perceber a inadequação de qualquer teoria filosófica. Mas isto é tudo: nos livramos da teoria e dos problemas que a acompanham e não ficamos com nenhum saldo filosófico positivo.

Stern sintetiza, assim, a discordância de pirrônicos e não-pirrônicos: o que está sendo apresentado é um método geral ou objeções a maus usos filosóficos de palavras? (STERN, 2004, p.127-126). Talvez pudéssemos formular assim a dificuldade de leitura: Wittgenstein está oferecendo um método para lidar com problemas filosóficos ou mostrando, por meio de exemplos, uma técnica (ou conjunto de técnicas) para resistir à tentação de propor teorias filosóficas? Há como decidir entre as duas leituras? Decidir se o que está sendo apresentado é um método filosófico ou objeções a posições particulares? Há, como já foi notado, evidência prima facie de que o que está sendo apresentado nestas seções é algo como um resultado positivo. Isto é sugerido pela mudança de estilo com relação às seções precedentes. E que se trata de considerações normativas é sugerido pelo uso reiterado de "deve" (ocorre quatro vezes em $\S 109$, novamente em $\S 116, \S 117, \S 120$ e $§ 124)$ e de expressões como "é tarefa da filosofia" (em §125) e “o trabalho do filósofo é” (em §127). Mas o defensor da leitura pirrônica pode não ficar satisfeito com essas evidências estilísticas. Ele pode inclusive argumentar que essas diferenças em estilo são mais prontamente explicadas pelo fato de que essas seções foram escritas pelo menos sete anos antes das seções circundantes. O que mais podemos dizer? Bem, podemos pressionar mais cada uma das leituras testando-as contra o texto. A leitura não-pirrônica, segundo a qual um método é apresentado ali, é a leitura natural destas passagens, tanto que foi adotado pela maioria dos comentadores (não precisamos ainda entrar no mérito quanto a que método é este). Quão bem a leitura pirrônica se ajusta a estas passagens? Em que medida podemos ler essas passagens como contendo não um método, mas uma "fonte de exemplos de alternativas aos pronunciamentos dogmáticos do filósofo tradicional" sobre como as coisas devem ser (STERN, 2004, p.127)?

A leitura pirrônica se ajusta bem aos parágrafos que tratam explicitamente de linguagem ordinária, como $§ 116$ e $§ 117$. Podemos lê-los não como expondo um aspecto de um método, mas como resumindo uma estratégia de resistência a teorias filosóficas ${ }^{2}$. Leríamos então este parágrafo como fornecendo uma dica para quem não quer se deixar seduzir por certa teoria 
filosófica: “veja, se estás às voltas com uma teoria filosófica sobre o 'saber', 'ser', 'eu', 'proposição' etc, um bom modo de resistir aos seus encantos é o seguinte: tome estas palavras como são usadas cotidianamente, tente enunciar a tese e veja se ela ainda faz sentido". Aí temos não um método de fazer filosofia, mas uma técnica de resistir à tentação de fazer filosofia.

A leitura pirrônica parece em perfeita sintonia também com considerações feitas ao final das ditas seções metodológicas. Em $§ 133$ é dito que "a verdadeira descoberta é a que me torna capaz de romper com o filosofar, quando quiser". E parece que é exatamente isso que a técnica pirrônica pode oferecer se bem-sucedida - um rompimento com a filosofia. Ainda no mesmo parágrafo a afirmação de que "não há um método da filosofia, mas sim métodos, como que diferentes terapias" parece reforçar a leitura pirrônica. Poderíamos dizer "não há um método de fazer filosofia, há várias técnicas terapêuticas para nos livrar da doença que é a tentação de fazer filosofia".

Há, contudo, várias passagens que não são acomodadas pela leitura pirrônica. Tratam-se das passagens onde o que se apresenta não são recomendações para se apelar à linguagem ordinária quando avaliamos teorias filosóficas mas considerações de caráter (ao menos na superfície) geral sobre a filosofia ou a tarefa da filosofia. Mais especificamente são os parágrafos nos quais o aspecto descritivo, em oposição ao aspecto teorético, da filosofia é enfatizado.

Tome por exemplo a afirmação em $§ 126$ de que "a filosofia simplesmente coloca as coisas, não elucida nada e não conclui nada". Como isto pode ser lido como uma estratégia de resistência a teorias filosóficas? Para que fonte possível de exemplos de alternativas a teorias filosóficas particulares este pronunciamento pode apontar? Que tipo de dica ele dá? "Diante de uma teoria filosófica veja se ela explica algo". Bem, a teoria filosófica $F$ tenta explicar como uma palavra significa aquilo que ela significa. Por que me dar conta disso me ajuda a resistir à tentação de assentir a $F$ ? Se eu já sei que a filosofia deve apenas descrever e não explicar, então essa constatação me ajuda a resistir a $F$, mas admitir isso é simplesmente admitir a validade da recomendação metodológica segundo a qual a filosofia não deve 


\section{POR QUE DEVERÍAMOS GIRAR O EIXO DA INVESTIGAÇÃO?}

explicar mas apenas descrever.

E quanto a "toda elucidação deve desaparecer e ser substituída apenas por descrição" (§109)? A dica é simplesmente que se tivermos uma descrição adequada das coisas encontraremos contraexemplos? Bem, se fizermos isso provavelmente acharemos contraexemplos para muitas teorias filosóficas pouco sofisticadas. Mas é isto que é dito ali? Isso seria o mesmo que dizer "para resistir a uma teoria filosófica mostre que ela não corresponde aos fatos, mostre que é errada ou falsa" - este conselho não é de muita ajuda. Mas aqui provavelmente estou sendo injusto: os resultados almejados por Wittgenstein e, portanto, os resultados para os quais seu método de resistir à filosofia seria talhado não são estes. Quer dizer, ele não se empenharia em resistir a teorias filosóficas buscando mostrar, com relação a cada teoria com que se deparasse, que ela é falsa, que há contraexemplos a ela. As Investigações abrem com a consideração da "visão agostiniana" a respeito da linguagem $(\S 1)$ e, como nota Cavell (1995, p. 265), ele não diz a respeito da passagem de Agostinho que, enquanto teoria filosófica, ela seja falsa, ou errada, ou que não haja evidência suficiente em seu favor, ou que ela contenha uma contradição, ou que possamos encontrar um contraexemplo a ela. Ele não utiliza nenhum termo de crítica convencional para atacar a passagem de Agostinho. O que ele se pergunta é se a passagem serve para algo, se é útil, e sua resposta é "Sim, é útil; mas apenas para esse domínio estritamente delimitado, não para o todo que você pretendia descrever" (§3). Em §2 ele apresenta um exemplo que se conforma perfeitamente a explicação do funcionamento da linguagem extraída da passagem em $\S 1$ e que, contudo, ao mesmo tempo, mostra quão longe esta explicação está da nossa linguagem. A ideia parece ser a seguinte: tomemos a explicação dada do funcionamento da linguagem; agora construamos uma descrição da linguagem em funcionamento conforme esta explicação; em seguida, forneça uma descrição cuidadosa da linguagem independente da explicação; por fim, veja quão diferentes são a descrição orientada pela explicação e a descrição que atenta ao fenômeno da linguagem, veja quão limitada era a explicação, como é pequeno o âmbito de funcionamento da linguagem que ela explica. Certamente esta é uma recomendação muito mais sofisticada do que "busque contraexemplos", mas a que ela se reduz afinal? Me parece que o que é dito é isto: "para resistir a uma teoria filosófica mostre que ela não atende a seus propósitos, que ela é severamente limitada, que ela alcança muito menos do que pretende alcançar". Essa seria uma dica melhor do que "para resistir a uma teoria, mostre que é falsa"; é algo como "se quer 
resistir a uma teoria, não procure mostrar que é falsa, procure mostrar que é limitada - e isso se faz descrevendo em detalhes o fenômeno do qual ela trata”. Esta é uma leitura possível, mas não é a mais natural. Nesse caso a explicação não é substituída pela descrição, é apenas denunciada em suas limitações. A leitura mais natural é esta: "se você se limitar a descrever corretamente as coisas não será necessária explicação, não restará problema para lhe perturbar". E isso é um conselho sobre como lidar com problemas filosóficos, não sobre como encontrar os meios para objetar ou resistir a uma teoria filosófica. Essa leitura é fortalecida pela constatação de que, pouco antes, em §109, Wittgenstein insiste na resolução de problemas pela descrição: “Os problemas são resolvidos não pelo acúmulo de novas experiências, mas pela combinação do que é já há muito tempo conhecido" (ênfase minha). A descrição é só um modo de apresentar o que já sabemos, e quando fazemos isso já não resta problema nenhum: "Como tudo fica em aberto, não há nada para elucidar. Pois o que está oculto não nos interessa" $(\S 126)$. O modo de proceder de Wittgenstein com respeito à passagem de Agostinho no início da obra pode ser assim compreendido: ele não está se esforçando para mostrar a limitação de uma teoria filosófica que é, contudo, correta para um propósito muito mais específico do que o pretendido; ele está, na verdade, tentando mostrar que os problemas que a suposta teoria contida na passagem de Agostinho resolveria simplesmente desaparecem quando temos uma descrição cuidadosa - eles surgem somente porque tomamos uma imagem severamente limitada como toda a imagem do funcionamento da linguagem. O parágrafo $\S 109$, portanto, também não se rende prontamente à leitura pirrônica.

Há então pelo menos algumas passagens que não cedem a uma leitura pirrônica e isso pode nos dar razão para ler outras passagens próximas e relacionadas, que poderiam ser lidas de maneira pirrônica, de maneira não-pirrônica. E essa evidência soma-se à evidência estilística prima facie para favorecer a leitura não-pirrônica. Então, se não temos um argumento decisivo, temos ao menos boas razões para supor que nestas passagens Wittgenstein apresenta um método positivo, indicações de como fazer filosofia, e não apenas sumariza seus esforços de resistir a certas teorias filosóficas.

Contudo, embora tenhamos aí um método para lidar com problemas filosóficos, não se trata 
de um método para construir teorias filosóficas (§109). O resultado positivo que a aplicação do método pode fornecer é o desaparecimento de problemas filosóficos, não um acréscimo de conhecimento. E aqui surge nosso principal problema, ao qual retornaremos: se isto está correto, o próprio método não pode ser um resultado filosófico positivo.

Segundo, e mais importante, a discussão com a leitura pirrônica deixa evidente que há uma tensão no texto. As recomendações em $\S \S 116-117$ são, como Wittgenstein nota em $§ 118$, puramente destrutivas - são recomendações de como resistir à filosofia, não de como lidar com problemas filosóficos. Já seções como $§ 109$ e $§ \S 124-127$ são evidentemente considerações sobre o que se deve buscar quando se faz filosofia e qual é a tarefa do filósofo. Essa tensão se acentua quando lemos no final de $§ 133$ que não há apenas um, mas vários métodos filosóficos.

A tensão decorre do seguinte: Wittgenstein tem várias técnicas descritivas que servem para resistir a teorias filosóficas particulares, mas isso não significa que devemos deixar de fazer filosofia e de lidar com problemas e inquietações filosóficas - é apenas o caso de que precisamos reconceber (ou melhor, esclarecer) a tarefa da filosofia e, com ela, a natureza do problema filosófico. O que é apresentado em $§ \S 108-133$ não é propriamente um método, mas aspectos de um desiderato metodológico ligado à recém-apresentada concepção da tarefa da filosofia. Este desiderato é o que é expresso em §108: "o eixo de referência de nossa examinação deve ser rotacionado, mas sobre o ponto fixo de nossa real necessidade"³. Precisamos agora esclarecer esta passagem.

\section{De que método se trata? Girando a Investigação}

Quero argumentar agora que em $\S \S 89-108$ Wittgenstein está expondo o que ele crê ser uma concepção errônea da tarefa da filosofia e do papel da lógica nesta investigação. Nisso estou de acordo com a leitura de Baker e Hacker (2005, p.251-252), embora não queira me pronunciar a respeito da questão de se a concepção sob ataque é aquela que Wittgenstein sustentou no Tractatus.

A concepção sob escrutínio nessas seções é acusada por Wittgenstein de sublimar a lógica. E 
podemos já dizer isto: rotacionar o eixo da investigação envolve abandonar a concepção sublime da lógica. Mas que concepção é esta e por que devemos abandoná-la?

Logo após se perguntar se a lógica é em alguma medida sublime, Wittgenstein parece apresentar o que são razões que nos levam a aceitar esta aparente sublimidade ( $\$ 89 b)$. A lógica seria sublime por sua singular profundidade, por investigar a essência de todas as coisas, muito embora não esteja preocupada com o modo como as coisas são de fato. Ela seria um esforço para compreender o fundamento de tudo o que pertence à experiência. Essa investigação teria por fim compreender algo que temos diante do olhos, mas que, em algum sentido, não conseguimos compreender. Imediatamente em seguida ( $\$ 89 \mathrm{c})$ ele cita uma passagem de Santo Agostinho na qual é enunciado um típico problema filosófico: "O que é, por conseguinte, o tempo? Se ninguém me perguntar, eu sei; se quiser explicar a quem me fizera a pergunta, já não sei”. Ora, aquilo que sabemos quando não refletimos a respeito, mas que não sabemos quando questionados e obrigados a refletir parece ser um bom candidato para uma investigação do tipo apresentado antes: investigar algo que temos diante dos olhos mas parecemos não compreender.

Isso sugere que a tendência a sublimar a lógica está relacionada à investigação de questões filosóficas. Podemos ler então os dois parágrafos seguintes ( $§ 90-91)$ como indicando o modo como no decorrer desta investigação poderíamos ser levados a sublimar nossa linguagem. Em $\$ 90$ Wittgenstein afirma que quando nos empenhamos numa investigação deste tipo, apesar de sentir como se tivéssemos que "desvendar os fenômenos", procedemos refletindo sobre "o modo das asserções que fazemos sobre os fenômenos" - procedemos por meio de considerações gramaticais. A investigação deveria então lançar luz sobre o problema por meio de considerações gramaticais que afastariam mal-entendidos. Um modo natural de fazer isso é substituir uma expressão por outra (analisar a expressão). Em §91, contudo, é notado que isto pode levar à ideia de que podemos fornecer uma análise última da nossa linguagem, que tornaria toda expressão perfeitamente clara e resolveria todo e qualquer malentendido possível. E essa ideia é naturalmente acompanhada pela ideia de que toda expressão habitual é não-analisada e oculta uma forma mais clara e exata. 


\section{POR QUE DEVERÍAMOS GIRAR O EIXO DA INVESTIGAÇÃO?}

O movimento apresentado nesses parágrafos é aquele pelo qual passamos, por um passo não justificado e quase despercebido, da trivialidade segundo a qual uma expressão pode ser substituída por outra no contexto da elucidação de um mal-entendido à concepção segundo a qual cada expressão oculta uma estrutura determinada que pode ser apresentada com perfeita clareza e que é esta estrutura que determina o sentido da expressão. Essa concepção é apresentada em $\S \S 99-101$, onde se trata da tentação de afirmar que toda expressão deve ter um sentido totalmente determinado e nada vago (que consiste na sua forma lógica totalmente analisada). Temos então uma imagem da linguagem ordinária como ocultando sob sua superfície uma estrutura complexa e perfeitamente exata que como que opera em segundo plano, garantindo a possibilidade de funcionamento da linguagem ordinária.

Encontramos aqui então um dos sentidos de "sublime" apontados por Mulhall (MULHALL, 2001, p.88): o sublime como subliminal. Nesse sentido, a lógica seria sublime porque se ocupa de desenterrar aquilo que voa abaixo do radar da nossa consciência ordinária; ela busca essa suposta estrutura extremamente complexa com a qual sempre operamos, mas que passa despercebida, camuflada, no nosso uso cotidiano da linguagem. Esse sentido de sublime já era apontado em $\S 89$ quando Wittgenstein enfatizava o caráter de profundidade da lógica. Quando essa concepção de lógica recebe um papel de destaque na investigação filosófica somos levados a questões sobre "essências ocultas" que se encontram "abaixo da superfície” (\$92).

Mas esse sentido de "sublime" não captura sozinho o caráter peculiar, a estranheza, que a lógica tem na concepção sob escrutínio. Outro sentido de "sublime" está ligado à ideia de sublimação ou refinamento (ibid.). Esse sentido é apontado pelas considerações em $\S 89$ de que a lógica é sublime pois não se preocupa com acontecimentos concretos. Se damos o passo ilustrado em $\S \S 89-91$ e concebemos a lógica como expondo a estrutura perfeitamente determinada e rígida que subjaz à linguagem, quando nos dermos conta de que a linguagem “está em ordem tal como está" (\$98) tenderemos a supor que isto se dá justamente porque a linguagem ordinária incorpora essa estrutura que imaginamos. Concebemos, então, a lógica como o esqueleto da linguagem, que poderia ser retirado dela e por um processo de refinamento apresentado em sua forma pura - como um "puro cristal” (§97). 
E obtemos uma imagem acabada da lógica sublime se atentamos a outras ilusões que vem se somar a essas (§96). Em especial, se tomamos a lógica como a estrutura subjacente não só da linguagem, mas também do nosso pensamento, essa noção da lógica como a ordem subjacente à linguagem leva à ideia de que essa ordem deve ser capaz de refletir as possibilidades do nosso pensamento, e portanto, do mundo (\$97) - de maneira que a lógica nos permite ver ao fundo não só a estrutura subjacente a nossa linguagem mas a essência mesmo de qualquer mundo possível. E aqui temos a imagem da lógica como sublime no sentido de extrema elevação, de algo monstruoso e incrível que provoca em nós um sentimento de reverência, admiração e temor (MULHALL, 2001, p.88) - pois que ciência extraordinária seria essa de ver a estrutura escondida por detrás do mundo!

Esta concepção da lógica e o papel que lhe é atribuído na investigação filosófica, contudo, é uma ilusão, fruto de um mal-entendido. Em última instância, é fruto da má compreensão da trivialidade segundo a qual resolvemos mal-entendidos substituindo uma expressão por outra - que leva, se cedemos à tentação de generalização, à ideia de uma análise, por meio de tais substituições, que chega a um nível de perfeita exatidão.

Como nos livramos desta concepção da lógica sublime? Wittgenstein nos diz que "quanto mais exatamente consideramos a linguagem de fato, tanto maior torna-se o conflito entre ela e nossas exigências" (§107); exigências estas que são projetadas a partir de nossa concepção errônea da lógica. "O preconceito da pureza cristalina só pode ser afastado se rotacionarmos toda nossa investigação (poder-se-ia dizer: o eixo de referência de nossa examinação deve ser rotacionado, mas sobre o ponto fixo de nossa real necessidade)" (§108). Bem, como estava orientada nossa investigação? Como Mulhall sugere (2001, p.92), sob a concepção sublime da lógica, a investigação estava orientada verticalmente - buscando penetrar o fenômeno, procurando aquilo que estava abaixo da superfície, que era profundo e oculto. Rotacionar o eixo o deixaria na horizontal - ao invés de buscar a profundidade, nos ateríamos à superfície. E isso está de acordo com as recomendações metodológicas feitas nas seções seguintes; está de acordo com a ênfase na descrição do que está ao alcance da vista e com o descaso para com o que está oculto $(\S 126)$. 
POR QUE DEVERÍAMOS GIRAR O EIXO DA INVESTIGAÇÃO?

Nossa questão sobre o método pode então ser reformulada: por que devemos girar assim a investigação? Por que devemos preferir uma investigação horizontal?

\section{Método, Descrição e Decisão}

Como devemos responder essa questão? Alguém pode dizer: "já que recusamos a abordagem vertical, nos resta a abordagem horizontal". Mas por que não posso, ao invés de adotar a abordagem horizontal, fazer como o pirrônico e simplesmente me ocupar de resistir a teorias filosóficas particulares? Por que preciso de uma abordagem específica? A resposta deve mostrar que a abordagem horizontal promete certos resultados. Mas como justificamos essa afirmação?

Não podemos apelar a uma filosofia de segunda ordem para determinar o método filosófico correto. Wittgenstein nega que haja uma filosofia de segunda ordem para tratar da palavra "filosofia" (§121). Aquilo que o filósofo tem a dizer a respeito da filosofia, e de seu método, deve ter a mesma qualidade daquilo que ele tem a dizer sobre outro tópico de interesse filosófico qualquer; deve respeitar as mesmas restrições metodológicas.

Portanto, as considerações filosóficas feitas sobre a filosofia, assim como outras considerações filosóficas quaisquer, também não podem ser teorias ou teses: "e não devemos construir nenhuma espécie de teoria” (§109). Elas podem ser apenas uma descrição ou uma imagem que articulam aquilo que já sabemos a respeito da filosofia, de modo a resolver malentendidos que podem surgir em torno dessa noção: "os problemas são resolvidos não pelo acúmulo de novas experiências, mas pela combinação do que já é há muito tempo conhecido" $(\S 109)$.

Suponha então que consigamos oferecer uma imagem de um modo ideal de proceder em filosofia. Suponha que o método seja oferecido na forma de um modelo. Contudo, mesmo tal modelo, algo que apresentasse uma descrição fiel de um paradigma de fillosofia, não teria peso normativo. As próprias recomendações metodológicas de Wittgenstein incluem restrições a tomar modelos como ideais aos quais a realidade deva se conformar: 
Só podemos evitar a injustiça ou o vazio de nossas afirmações, na medida em que apresentamos o modelo como o que ele é, ou seja, como objeto de comparação - por assim dizer, como critério -; e não como préjuizo, ao qual a realidade deva corresponder (§131).

Não podemos tomar aquilo que é apresentado em $\S \S 108-133$ como um modelo ao qual o bom filosofar deva se conformar ${ }^{4}$. Então parece que não podemos fornecer uma resposta para nossa questão; pois de que pode servir um método que não tem nenhuma força normativa? De que serve um método do qual não podemos dizer que a prática deva se conformar a ele?

Bem, tudo que podemos apresentar é um modelo de comparação. O que podemos fazer com isso? Para que serve uma modelo de comparação? Wittgenstein tem o seguinte a dizer: “jogos de linguagem figuram muito mais como objetos de comparação, que através de semelhanças e dissemelhanças devem lançar luz sobre as relações de nossa linguagem" $(\S 130)$.

Modelos, na medida em que são objetos de comparação, não são primeiras aproximações de um ideal com força normativa. Objetos de comparação servem para lançar luz sobre o fenômeno com o qual nos ocupamos, e fazem isso ao permitir que vejamos semelhanças e dissemelhanças. Uma régua, por exemplo, é um objeto de comparação. O que fazemos com ela? Para que serve? Comparamos uma régua com algo, não como um ideal ao qual a coisa deva ser conformar, mas com um propósito específico: determinar o comprimento do objeto. A régua esclarece um aspecto do objeto (seu comprimento) na medida em que nos permite ver que o objeto e régua tem ou não tem o mesmo comprimento.

Agora, a régua não tem nenhuma força normativa? Melhor, a prática de medir não tem nenhuma consequência normativa? Ora, suponha que estou construindo uma mesa e quero que o tampo tenha um metro de comprimento. Pego a régua de um metro e verifico que o comprimento da mesa não corresponde ao comprimento da régua. A utilização do objeto de comparação me permite ver esta discrepância. Isso, combinado com meu propósito específico (determinar se o comprimento precisa ser alterado para que a mesa se conforme a meu 
plano), gera uma consequência normativa: o tampo da mesa deve ser diminuído. O fato é que, embora a prática de medir usando um objeto de comparação quando considerada em isolado não apresente nenhum aspecto normativo, em contextos concretos tais práticas estão, em geral, relacionadas a nossa tomada de decisão e neste sentido participam de atividades normativas.

Objetos de comparação geralmente são criados para servirem a um propósito em certa prática que envolve certos fins e nesse contexto estes objetos têm força normativa e moldam nossas decisões. Se o que Wittgenstein está oferecendo é um modelo de filosofia, este pode obter força normativa se combinado com certos fins particulares. Que fins? Ora, os fins que temos em vista quando filosofamos. Que fins são estes? Isto determinamos por meio de uma observação cuidadosa do que fazemos quando filosofamos: atentando ao que são problemas filosóficos, como procedemos ao tentar resolvê-los e o que conta como uma solução satisfatória. E isso é o que está, em grande parte, sendo feito em $§ 108-133$. Wittgenstein tem algo a dizer, por exemplo, sobre o que são problemas filosóficos (§123), sobre como surgem (§111) e em que consiste um resultado em filosofia (§119). Mas como se pode fazer isso? Isso se faz descrevendo casos históricos de pessoas que fizeram filosofia. A imagem que Wittgenstein apresenta da natureza da filosofia deve, portanto, de maneira a ter algum valor normativo como recomendação metodológica, estar conectada à tradição filosófica, deve ter em vista uma descrição daquilo que esta tradição fazia quando fazia filosofia.

Esse desiderato é atendido? Sim, e era este o esforço de Wittgenstein nas passagens anteriores, $\S \S 89-108$. A discussão nessas seções, como foi exposto na seção 3 deste trabalho, começa apresentando o movimento pelo qual passamos da trivialidade, segundo a qual uma expressão pode ser substituída por outra no contexto da elucidação de um mal-entendido, a uma concepção sublime da lógica. Esse passo é feito no contexto de investigações filosóficas em que estamos às voltas com questões como a questão de Agostinho sobre o tempo $(\S 89 \mathrm{c})$ questões sobre coisas que em certo sentido já sabemos, mas que exigem reflexão. Como Wittgenstein nota em $\S 90$, procedemos nessa investigação por meio de considerações gramaticais, refletindo sobre diferentes coisas que dizemos a respeito do fenômeno que nos ocupa, de maneira a retirar mal-entendidos e permitir uma visão clara daquilo que já sabíamos. Isso pretende ser uma descrição daquilo que filósofos tradicionalmente fizeram, 
muito embora alguns filósofos tenham, partindo dessa descrição, representado para si mesmos sua atividade de outra forma, o que os levou a conceber sua tarefa não como a tarefa de resolver mal-entendidos sobre o que já sabemos, mas como a tarefa de revelar algo escondido abaixo da superfície da linguagem ou do mundo.

Então, as passagens anteriores às recomendações metodológicas de Wittgenstein se ocupam de apresentar o fim que temos em vista quando engajamos na atividade histórica de fazer filosofia: nos ocupamos de remover mal-entendido para ver claramente algo que já sabíamos. Podemos de alguma forma deduzir desse fim o método proposto em $\S \S 108-133$ ? Creio que não; não mais do que podemos deduzir a partir do fato de que temos como nosso fim determinar o comprimento de algo que devemos usar uma régua. Poderíamos chegar à conclusão de que podemos medir algo usando a palma da mão e que isto bastaria. A decisão de usar uma régua como objeto de comparação ou outro método depende de um processo de deliberação que leva em consideração não apenas nossos fins, mas outras circunstâncias, como, por exemplo, o nível de precisão que desejamos e o que temos à disposição.

Da mesma forma, uma descrição acurada do fimm que temos ao filosofar não leva, necessariamente, às recomendações metodológicas de Wittgenstein. Estas recomendações não têm um caráter especial - como se fossem deduzidas a priori da noção de filosofia ou porque fossem condição necessária para realizar esta atividade. Mas uma descrição acurada do fim da filosofia nos permite deliberar corretamente sobre que método adotar. Se estivéssemos ainda sob a impressão de que o fim que temos em vista ao filosofar é desvelar a estrutura subjacente à realidade, adotaríamos um método muito diferente do método horizontal que Wittgenstein oferece; adotaríamos um método verticalizado. Dado que sabemos que nosso fim é remover mal-entendidos sobre coisas que já sabemos, ao deliberarmos sobre como realizar esse fim é de se esperar que cheguemos a uma conclusão como: não precisamos fazer teorias para compreender o que já sabemos; não precisamos procurar por nada escondido, algo que não conseguimos ver; basta que chamemos atenção para coisas que já sabemos; basta fazer lembretes para que não nos esqueçamos novamente dessas coisas; não há necessidade de explicar, basta apresentar uma representação panorâmica do que já temos a nosso alcance para evitar a confusão, etc. 
A aplicação do método descritivo à filosofia, tomada como um fenômeno passível de investigação filosófica como qualquer outro, não mostra, num sentido forte, a correção de uma abordagem horizontal, mas ao menos nos dá material para uma deliberação mais informada a respeito de como proceder na busca do fim que temos em vista ao filosofar simplesmente porque nos aponta com clareza que fim é esse. Em última instância, a adoção de um método horizontal depende de uma decisão sobre qual é o melhor modo de realizar o fim que perseguimos; mas, como qualquer outra decisão que tomamos em nossa vida, esta não é uma decisão totalmente arbitrária: é fruto de um processo deliberativo ordinário. Podemos expor assim a tese que defendemos: o "deve" nas recomendações metodológicas de Wittgenstein pode não ser um "deve" do imperativo categórico, mas ao menos ele pretende que seja o "deve" de um imperativo hipotético. É como o "deve" em: "se você quer chegar à cidade indicada pela placa, você deve seguir este caminho". O único motivo pelo qual as recomendações metodológicas parecem contrastar tanto com o método de outros filósofos é porque eles pensaram que seu destino era outro - porque representaram de maneria errônea o fim que perseguiam (o que foi mostrado nas seções $\S \S 89$ ss)

\section{Conclusão}

Na seção 1 foi dito que argumentaríamos quanto a dois pontos: (i) que Wittgenstein faz recomendações metodológicas positivas e (ii) a respeito da justificação dessas recomendações.

Quanto a (ii) nossa conclusão foi que apesar de as afirmações taxativas em $\S \S 108-133$ não terem sido demonstradas ou provadas elas estão justificadas em certo sentido, talvez o único sentido em que um método possa ser justificado. Elas estão justificadas na medida em que são resultado de um processo de deliberação fidedigno, pois equipado com crenças adequadas sobre o fim que buscamos. Esse método para resolver problemas filosóficos está então justificado da mesma maneira como justificamos a adoção de métodos para resolver outros problemas práticos, por exemplo, o método de usar a régua para medir. As crenças que formam a base da deliberação, contudo, são fornecidas pela aplicação do método de investigação filosófica sobre a noção de filosofia ela mesma. Isso não torna a justificação do 
método circular? Creio que não; caso o método fosse deduzido da noção de filosofia mediante sua própria aplicação este seria o caso. Mas o método não é fruto de uma dedução, ele é resultado de uma escolha prática. Que seja a aplicação do método que fornece o material para a deliberação que resulta nessa decisão não determina nossa escolha do método. O método não é pressuposto pela deliberação, apenas fornece o material para ela de maneira a garantir sua fidedignidade. A deliberação tem suas próprias regras. É dessa maneira que o método contribui para sua própria justificação sem incorrer em circularidade.

Quanto a (i), afirmei ao final da seção 2 que o que Wittgenstein tinha a oferecer não era exatamente um método, mas um desiderato metodológico expresso em $§ 108$ : “o eixo de referência de nossa examinação deve ser rotacionado, mas sobre o ponto fixo de nossa real necessidade". O ponto fixo da nossa necessidade é o fim que queremos realizar. Isso faz justiça à afirmação em $\S 133$ de que não há apenas um método em filosofia, mas vários métodos como várias terapias. A deliberação não precisa resultar na adoção de um método apenas. Contudo, dada nossa concepção do fim da filosofia ao menos isso parece resultar de qualquer deliberação sensata e bem informada: para atender esse fim devemos adotar uma abordagem horizontal, devemos descrever e não teorizar; não devemos tentar criar hipóteses e descobrir coisas quando estamos preocupados em esclarecer algo que já sabemos. Mas vários métodos, adequados a problemas filosóficos diferentes, todos satisfazendo este desiderato geral, podem ser adotados em circunstâncias diferentes. E isso explica a tensão que o leitor pirrônico percebe no texto: há vários métodos que podem ser usados para dissipar ilusões filosóficas, mas todos eles devem ser horizontais se pretendem ser adequados para resolver problemas filosóficos.

\section{Referências Bibliograficas}

BAKER, Gordon \& HACKER, Peter. Wittgenstein:Understanding and Meaning: Part I: essays. 2.ed. Oxford: Blackwell Publishing Ltd, 2005

CAVELL, Stanley. Notes and Afterthoughts on the opening of Wittgenstein's Investigations. In: SLUGA, H. \& STERN, D. The Cambridge Companion to Wittgenstein. Cambridge: Cambridge University Press, 1996, p.261-295 
MCGUINN, Marie. Wittgenstein and the Philosophical Investigations. 2.ed. London: Routledge, 2002.

MULHALL, Stephen. Inheritance and Originality: Wittgenstein, Heidegger, Kierkegaard. Oxford: Clarendon Press, 2001

. Philosophy's hidden Essence : PI 89-133. In: AMMERELLER, E. \& FISHER, E. Wittgenstein at Work: Method in the Philosophical Investigations. London: Routledge, 2004, p.63-85

STERN, David. Wittgenstein's Philosophical Investigations: An Introduction. New York: Cambridge University Press, 2004

WITTGENSTEIN, Ludwig. Investigações Filosóficas. Tradução de José Carlos Bruni. São Paulo: Editora Nova Cultural, 2000. 